\title{
Improving Mental Health during the COVID-19 Pandemic through Online Psychoeducation
}

\author{
Kartika Nur Fatbiyab' ${ }^{1}$; Tria Widyastuti'; Farida Agus Setiawati'; Rabmatika Kurnia Romadhani'; Yulia \\ Ayriza ${ }^{1} ;$ Yabya Abdullab ${ }^{1}$; Lu'lu Inayatul Lilmuallafah ${ }^{1}$ \\ ${ }^{1}$ Department of Psychology, Universitas Negeri Yogyakarta, \\ Jl. Colombo No. Depok, Sleman, Yogyakarta 55281, Indonesia \\ kartika@uny.ac.id
}

\begin{abstract}
The COVID-19 pandemic alters many aspects of everyday life that we have grown accustomed to. The enactment of various new policies to curb the spread of the disease, i.e., social distancing, work and study from home, restrictions on large-scale activities and restriction in travelling, compel each one of us to adjust. Not to mention the fear of being infected with COVID-19. These conditions led to various psychological problems such as anxiety, low hope, and negative emotions. Efforts to improve people's mental health are urgently needed. One such step is to increase one's understanding of self-management in facing psychological problems due to COVID-19. This study aims to improve the community's mental health, namely the residents of Blotan hamlet during the COVID-19 pandemic through online self-management psychoeducation. To test the effectiveness of psychoeducation, this study used a one-group pre and post-test design. A total of 31 subjects participated in the activity in full. We can infer the effectivity through the anxiety score, hope, and positive emotions on the pre and post-test measurements. The results found that self-managed psychoeducation facing psychological problems during the pandemic significantly increased positive emotions $(t=-2,753, \mathrm{df}=30$, and $\mathrm{p}<.05)$. As for the measurement of anxiety and hope, there was no significant change due to the subject's anxiety score and hope were already in the medium category.
\end{abstract}

Keywords: COVID-19; positive emotion; mental health; psychoeducation

\section{Introduction}

The spread of the COVID-19 virus threatens public health around the world. Reporting from the World Health Organization website, on April 14, 2020, there were 1,848,439 confirmed cases of Covid-19 with 117,217 deaths (World Health Organization, 2020b). In Indonesia, COVID-19 was first detected on March 2, 2020, and the number of victims is increasing from time to time. As for Indonesia itself, there have been 4,839 confirmed positive cases of Covid-19, with 459 people dying related to COVID-19 (World Health Organization, 2020a). To minimize the spread of the COVID-19 virus, the government issued social/physical distancing policies, lockdowns, policies for studying, doing activities, and working at home, as well as limiting large-scale activities. Implementing these various policies creates psychological problems for the community (Grover et al., 2020). Increased stress due to termination of employment, closure of business premises, lonely sales, demands for adjustment to a new lifestyle as access to various policies creates pressure (stressors) for the community. Stress also arises due to financial uncertainty, insufficient food supply, and limited activities (Khan et al., 2020). These various circumstances trigger the emergence of helplessness. In some individuals, there is a failure to tolerate the situation. Inability to tolerate circumstances 


\section{Improving Mental Health during the COVID-19 Pandemic Fathiyah, Widyastuti, Setiawati, Romadhani, Ayriza, Abdullah \& Lilmuallafah}

makes the stressor feel exaggerated, exceeding one's capacity to face it. This raises various psychological problems.

Psychological problems that arise include anxiety, depression, and stress (Ho et al., 2020; Khan et al., 2020; Liu et al., 2020; Xia et al., 2020). Research by Li, Wang, Xue, Zhao, and Zhu (2020) also reported an increase in negative emotions (anxiety, depression, and anger) and sensitivity to social risks and decreased positive emotions and life satisfaction after the Covid-19 declaration. The longer the quarantine period is also reported to have a role in psychological distress (Ho et al., 2020). The existence of various psychological problems indicates the need for efforts to increase self-capacity in dealing with COVID-19. Steps that can be made include providing self-management understanding or psychoeducation to face psychological issues due to the COVID-19 outbreak. This can make people able to survive and carry out their daily activities optimally. Efforts to foster positive emotions during the Covid-19 outbreak are entirely meaningful because positive emotions are a source of personal coping in facing various problems. This is evidenced by multiple experimental studies in positive psychology that have found the role of positive affects such as joy, love, interest, contentment, hope, and gratitude in developing resilience to grow out of an adverse situation (Fredrickson et al., 2003).

Strengthening psychological capacity through the provision of material on hope is also considered essential. Hope is often closely related to the goal of survival or survival of humans. When hope is gone, then a person's desire to end their life arises. That is what happens to people who experience depressive disorders. Hope is often associated with optimism, future thoughts, and future orientation, a cognitive, emotional and motivational mental attitude towards the future (Peterson \& Seligman, 2004). Therefore, hope is proclaimed for the future when people face difficulties overcoming challenges and achieving the expected goals. There are three steps in the process of building hope (Snyder, 2000), namely: (1) Goal, (2) Agency, and (3) Pathways.

One way to reduce anxiety levels (Rummel-Kluge et al., 2009), foster positive emotions, and instil hope (Long et al., 2015) is psychoeducation. Psychoeducation is a good alternative because it is relatively easy to do and does not require much money (Donker et al., 2009). However, in the current COVID-19 pandemic, there is a need for adjustments in the implementation of psychoeducation because it will be challenging to do in person or face to face. Providing online psychoeducation is a safe choice during the COVID-19 pandemic. Several online mental health services were already in place during the COVID-19 pandemic in China (Liu et al., 2020). Some of the mental health services that have been implemented in China include online mental health education with WeChat, Weibo, TikTok during the Covid-19 pandemic for medical and general personnel. In addition, WeChat-based online psychological counselling is also carried out by various health institutions and universities.

Based on this background, we can conclude that one of the problems that arise due to the COVID-19 pandemic is mental health problems, including social restrictions that do not allow face-to-face mental health services that can be overcomed with the implementation of online service. Regarding the described issues, this study aims to examine the role of online psychoeducation to improve people's mental health during the COVID19 pandemic.

\section{Methods}

\section{Research design and data collection}

The research conducted is a quasiexperimental study that aims to test the effectiveness of online psychoeducation in 
improving mental health during the COVID-19 pandemic. The experimental design used was a one-group pre and posttest design. The research was conducted online on August 19, 2020, through the Google Meet platform.

\section{Research Subject}

A total of 36 study subjects filled out a pretest and took part in online psychoeducation on self-management of mental health during a pandemic. Then 32 participants filled out the post-test. The final number of research subjects involved in the final analysis was as many as 31 people. Details of research subjects from each stage of analysis can be seen in Figure 1. The final research subjects consisted of 2 men and 29 women aged 17 to 57 years $($ Mean $=37,193, \mathrm{SD}=12.31)$ with a junior high / high school education background $(49.4 \%), \mathrm{S} 1(38.7 \%), \mathrm{S} 2(6.5 \%)$, and S3 $(6.5 \%)$.

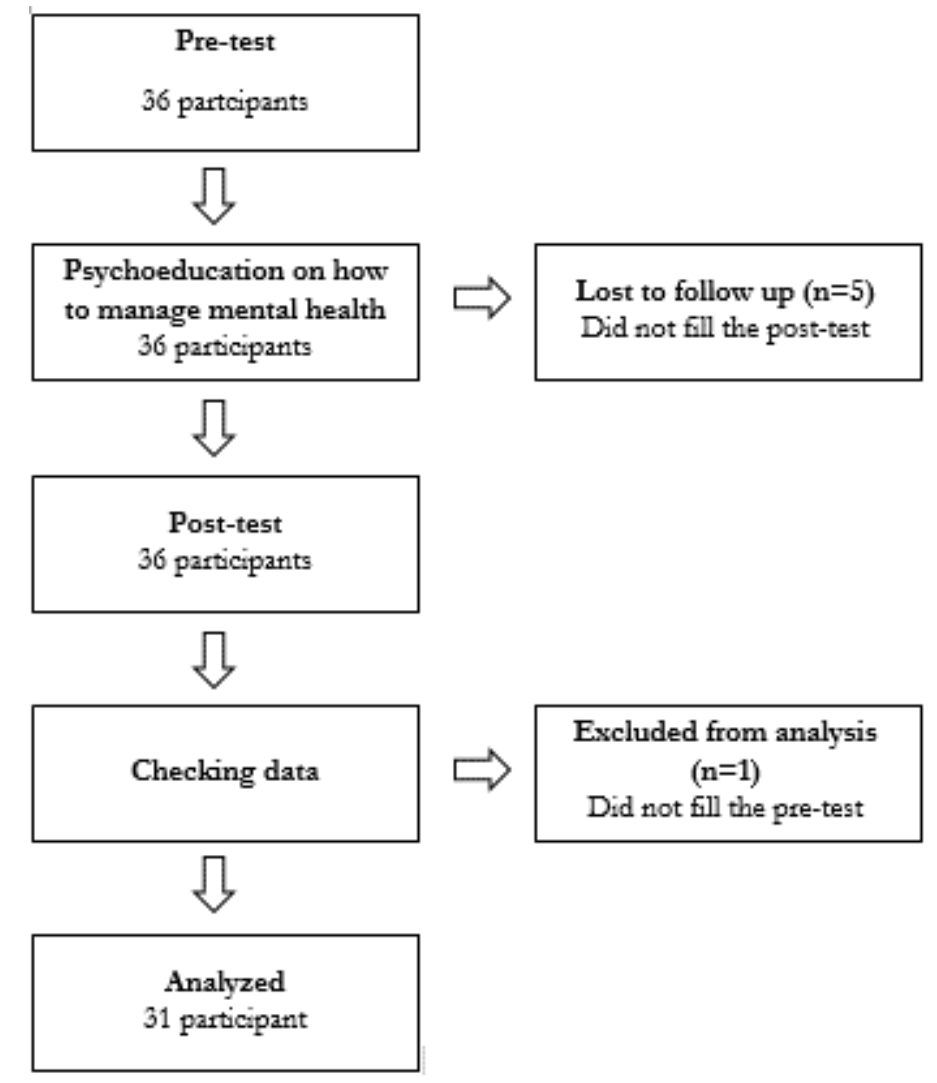

Figure 1. Flowchart of participants

Research Instruments

Researchers measured changes in participants' attitudes and behaviour after being given online psychoeducation about self-management of mental health using three measurement scales. The instruments used include: (1) the state part of the State-Trait Anxiety Inventory (STAI), (2) the hope scale, and (3) the positive emotion scale.
Anxiety measurements were performed using S-anxiety from the StateTrait Anxiety Inventory developed by Marteau and Bekker (1992). STAI measures state anxiety (S-anxiety) and trait-anxiety (T-anxiety). S-anxiety is a temporary emotional condition associated with tension, anxiety, nervousness, and worry whose intensity varies and changes over time (Spielberger \& Reheiser, 2004). Meanwhile, T-anxiety refers to anxiety 
that is relatively stable or part of the personality. STAI is still being developed in several countries, especially the short version of STAI (Zsido et al., 2020). This study used a 6-item version of S-anxiety from Marteau and Bekker's (1992) study. This version consists of 3 favourable items (items no. 2, 3, 6) and three unfavourable items (items nos. 1, 4, 5). In favourable items, the response option "not at all" was assigned a score of 1, "somewhat appropriate" was assigned a score of 2 , "quite appropriate" was assigned a score of 3, and "very appropriate" was assigned a score of 4. As for unfavourable items, the scoring was reversed. The 6-item Sanxiety score ranges from 6 to 24 . The $6-$ item version was found to have an alpha reliability coefficient of .82 and a high correlation of .95 with the long version of STAI. In this study, the reliability of the 6item S-anxiety was measured again and was found to be .626 .

Table 1.

Psychometric property of the research instruments

\begin{tabular}{llll}
\hline Instrument & $\begin{array}{l}\text { Total } \\
\text { Item }\end{array}$ & $\begin{array}{l}\text { Corrected-item } \\
\text { total correlation }\end{array}$ & Reliability $\boldsymbol{\alpha}$ \\
\hline State Anxiety & 6 & $.230-.423$ & .626 \\
Hope Scale & 4 & $.716-.893$ & .919 \\
Positive emotion scale & 3 & $.315-.538$ & .585 \\
\hline
\end{tabular}

The researcher compiled hope and positive emotions scale. The hope scale consists of 4 favourable items with a choice of responses from"very inappropriate", assigned a score of 1 , to "very suitable", assigned a score of 5 . The hope score ranges from 4 to 20 . The reliability estimate of the four hope items is 0.919 . The scale of positive emotions consists of 3 favourable items. The response options consisted of 5 choices from "very unsuitable", assigned a score of 1, to "very suitable", which was assigned a score of 5. Positive emotional scores ranged from 3 to 15 . The reliability of the three items of positive emotions was 0.585. The instrument reliability information can be seen in Table 1 .

\section{Research Procedure}

The study consisted of three stages, namely: (1) measurement before giving online psychoeducation (pretest), (2) giving online psychoeducation, and (3) measuring after giving online psychoeducation.

\section{1) Pretest}

The pretest was conducted to determine the subject's score of anxiety, hope, and positive emotions before being given psychoeducation about selfmanagement of mental health. The pretest was carried out by asking the subjects to fill in the scale online via the google form. In filling the scale, the subjects were guided by the researcher through google meet.

2) Online Psychoeducation

Self-managed mental health psychoeducation is conducted online, which includes the following materials: (1) challenges and the other side of the COVID-19 pandemic, (2) hope and survival during the COVID-19 pandemic, (3) mental health with positive emotions, (4) ) meaningful life, and (5) mindfulness. 3) Post-test

At the end of the session, the final measurement (post-test) was carried out via google form guided by the researcher. 
Data Analysis

The pretest and post-test scores of the final 31 subjects who completed both measurements were then analyzed. The analysis was carried out by using paired sample t-test using SPSS version 20 software.

\section{Findings}

Evaluation of the effectiveness of the provision of online mental health selfmanagement psychoeducation was carried out by testing the pretest and post-test results. In addition, the researcher also asked the subject to write a qualitative written evaluation related to the given online psychoeducation. The paired sample t-test result from the pretest and post-test measurements of anxiety, hope, and positive emotions can be seen in Table 2

Table 2.

Paired sample t-test result

\begin{tabular}{llccccc}
\hline & & Mean & Mean diff. & $\mathbf{t}$ & Df & sig \\
\hline \multirow{2}{*}{ Anxiety } & CPRE & 11.064 & .612 & 1.218 & 30 & .233 \\
\multirow{2}{*}{ Hope } & CPOST & 10.451 & & & & \\
\multirow{2}{*}{ Positive } & HPRE & 15.225 & -.064 & -.113 & 30 & .911 \\
Emotion & HPOST & 15.290 & & & & \\
\hline
\end{tabular}

The average anxiety score decreased after training, from 11,064 to 10,451 in the post-test $(\Delta=.613)$. However, this decrease in anxiety score was not significant $(\mathrm{t}=1.218 \mathrm{df}==30$, and $p>.05)$. Thus, there is no difference in anxiety before and after training. The average expected score increased from 15,225 in the pretest to 15,290 , with a prepost mean difference of -.0635. However, the increase in the hope score was not significant $(\mathrm{t}=-.113, \mathrm{df}=30$, and $\mathrm{p}>.05)$. Thus, there is no difference in hope before and after training. The mean score of positive emotions increased from 9,935 to $11,129(\Delta=-1.1935)$. The increase in positive emotional scores was significant $(t$ $=-2,753, \mathrm{df}=30$, and $\mathrm{p}<.05)$. Thus, there are differences in positive emotions before and after training. The positive emotions of the research subjects increased after attending the training.

\section{Discussion}

Based on the results of pretest and post-test measurements, the provision of self-managed mental health psychoeducation during the COVID-19 pandemic which consists of materials on: (1) challenges and the other side of the pandemic, (2) mental health by managing positive emotions, (3) managing hope, (4) managing the meaning of life, and (5) mindfulness significantly increasing participants' positive emotions. This is in line with $\mathrm{Yu}, \mathrm{Yu}$, and $\mathrm{Li}$ (2020) findings that mindfulness can minimize the negative impact of the COVID-19 pandemic on mental health. In addition, the material for managing positive emotions or emotion regulation also plays a role in increasing positive emotions. This finding is also reinforced by previous research that effective emotion regulation 


\section{Improving Mental Health during the COVID-19 Pandemic \\ Fathiyah, Widyastuti, Setiawati, Romadhani, Ayriza, Abdullah \& Lilmuallafah}

helps deal with the adverse effects of the COVID-19 pandemic (Restubog et al., 2020).

Even though anxiety decreased, the anxiety score decreased significantly. This is possible because the subject's anxiety score before giving psychoeducation (pretest score) was classified as moderate, namely 10,451. As explained in the method section, the 6item S-anxiety score range ranges from 6 to 24. This also occurs with the hope score, which is quite good from the start, with an average score of 15,225 as it is known that the score range for four items on the hope scale ranges from 4 to 20 . This may be explained by the adjustment of the community in facing the COVID19 pandemic. When the pandemic situation has become a daily routine, where people are used to living with masks and lockdown policies, the level of optimism starts to rise (Kaur et al., 2020).

The qualitative evaluation results after the post-test measurement showed that the subjects felt the benefits of providing mental health self-management psychoeducation. In terms of usefulness, the subject expressed appreciation that the psychoeducation activities provided were very good, helpful, provided enlightenment, provided understanding, to be more able to deal with psychological problems during the COVID-19 pandemic, and provided motivation not to be trapped in stress. In terms of implementation, the subject gave suggestions so that this psychoeducation activity could be carried out routinely. In terms of delivery, the subject reveals that the material presented is easy to understand.

Apart from appreciation, organizing psychoeducation online is inseparable from its shortcomings. The first limitation is technical constraints from the participants, such as an unstable internet connection. The second obstacle was that some participants could not attend until the end due to technical problems, such as low or exhausted cellphone batteries for participating in online psychoeducation activities.

\section{Conclusion}

Based on the measurement results before and after mental health selfmanagement psychoeducation, it can be concluded that the provision of mental health self-managed psychoeducation can significantly increase participants' positive emotions. Qualitatively based on a written evaluation of the subject, giving psychoeducation helps subjects better face psychological problems during the COVID-19 pandemic.

\section{Suggestion}

This activity may be carried out routinely because it is considered beneficial for the training participants. Further, the meeting might be divided into several meetings to discuss the material more deeply.

\section{References}

Donker, T., Griffiths, K. M., Cuijpers, P., \& Christensen, H. (2009). Psychoeducation for depression, anxiety and psychological distress: A meta-analysis. BMC Medicine, 7, 1-9. https://doi.org/10.1186/17417015-7-79

Fredrickson, B. L., Tugade, M. M., Waugh, C. E., \& Larkin, G. R. (2003). What good are positive emotions in crises? A prospective study of resilience and emotions following the terrorist attacks on the United States on September 11, 2001. Journal of Personality and Social Psychology, 84(2). https://doi.org/10.1037/00223514.84.2.365

Grover, S., Dua, D., Sahoo, S., Mehra, A., Nehra, R., \& Chakrabarti, S. (2020). 
Why all COVID-19 hospitals should have mental health professionals: The importance of mental health in a worldwide crisis! Asian Journal of Psychiatry, 51(April), 102147. https://doi.org/10.1016/j.ajp.2020. 102147

Ho, C. S., Chee, C. Y., \& Ho, R. C. (2020). Mental Health Strategies to Combat the Psychological Impact of COVID-19 Beyond Paranoia and Panic. Annals of the Academy of Medicine, Singapore, 49(1), 1-3.

Kaur, S., Kaul, P., \& Zadeh, P. M. (2020). Monitoring the Dynamics of Emotions during COVID-19 Using Twitter Data. Procedia Computer Science, 177, 423-430. https://doi.org/10.1016/j.procs.20 20.10.056

Khan, A. H., Sultana, M. S., Hossain, S., Hasan, M. T., Ahmed, H. U., \& Sikder, M. T. (2020). The impact of COVID-19 pandemic on mental health \& wellbeing among homequarantined Bangladeshi students: A cross-sectional pilot study. Journal of Affective Disorders, 277(June), 121128.

https://doi.org/10.1016/j.jad.2020. 07.135

Li, S., Wang, Y., Xue, J., Zhao, N., \& Zhu, T. (2020). The Impact of COVID19 Epidemic Declaration on Psychological Consequences: A Study on Active Weibo Users. Environmental Research and Public Health, 17. https://doi.org/http://dx.doi.org/ 10.3390/ijerph17062032

Liu, N., Zhang, F., Wei, C., Jia, Y., Shang, Z., Sun, L., Wu, L., Sun, Z., Zhou, Y., Wang, Y., \& Liu, W. (2020). Prevalence and predictors of PTSS during COVID-19 outbreak in China hardest-hit areas: Gender differences matter. Psychiatry
Research, 287, 112921. https://doi.org/https://doi.org/10 .1016/j.psychres.2020.112921

Long, C. G., Fulton, B., \& Dolley, O. (2015). Using psychoeducation to motivate engagement for women with personality disorder in secure settings. Journal of Psychiatric Intensive Care, 11(01), 18-26. https://doi.org/10.1017/s1742646 413000344

Marteau, T. M., \& Bekker, H. (1992). The development of a six-item shortform of the state scale of the Spielberger State-Trait Anxiety Inventory (STAI). British Journal of Clinical Psychology, 31(3), 301-306. https://doi.org/10.1111/j.20448260.1992.tb00997.x

Peterson, C., \& Seligman, M. E. P. (2004). Character strengths and virtues: $A$ bandbook andclassification. American Psychological Association.

Restubog, S. L. D., Ocampo, A. C. G., \& Wang, L. (2020). Taking control amidst the chaos: Emotion regulation during the COVID-19 pandemic. Journal of Vocational Behavior, 119(May), 1-6. https://doi.org/10.1016/j.jvb.2020. 103440

Rummel-Kluge, C., Pitschel-Walz, G., \& Kissling, W. (2009). Psychoeducation in anxiety disorders: Results of a survey of all psychiatric institutions in Germany, Austria and Switzerland. Psychiatry Research, 169(2), 180-182. https://doi.org/10.1016/j.psychres. 2008.10.016

Snyder, C. R. (2000). Handbook of hope: Theory, measures, and applications. Academic Press.

Spielberger, C. D., \& Reheiser, E. . (2004). Measuring anxiety, anger, depression, and osity as emotional 
states and personality traits with the STAI, STAXI, and STPI. In M. J. Hilsenroth \& D. L. Segal (Eds.), Comprehensive handbook of Psychological assessment. John Wiley\& Sons, Inc.

World Health Organization. (2020a). Update on coronavirus disease in Indonesia. April 14.

World Health Organization, W. H. O. (2020b). Coronavirus disease (COVID19) Pandemic. April 14.

Xia, J., Meng, Y., Wen, F., Li, H., Meng, K., \& Zhang, L. (2020). Caring for anxiety among adults in the face of COVID-19: A cross-sectional online survey. Journal of Affective Disorders Reports, 1(September), 100014.

https://doi.org/10.1016/j.jadr.202 0.100014

Yu, Y., Yu, Y., \& Li, B. (2020). Effects of mindfulness and meaning in life on psychological distress in Chinese university students during the COVID-19 epidemic: A chained mediation model. Asian Journal of Psychiatry, 53, 102211. https://doi.org/10.1016/j.ajp.2020. 102211

Zsido, A. N., Teleki, S. A., Csokasi, K., Rozsa, S., \& Bandi, S. A. (2020). Development of the short version of the spielberger state-trait anxiety inventory. Psychiatry Research, 291(January), 113223. https://doi.org/10.1016/j.psychres. 2020.113223 